\title{
Of ambivalence, shame and guilt: Perceptions regarding termination of pregnancy among South African women
}

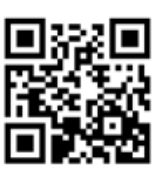

Termination of pregnancy (TOP) for health or other reasons is an emotive and contentious issue, steeped in the context of a political, moral and religious climate. For most women, the decision to have a TOP is not easy, regardless of the reason. While early literature ${ }^{[1-3]}$ supported the notion that that there is little in the way of negative sequelae following TOP, more recent long-term studies ${ }^{[4-6]}$ have suggested that negative sequelae may be more common than was previously thought. Risk factors for the development of negative sequelae include the attitude projected by those providing the procedure (negative attitudes of providers tend to promote emotional sequelae in women undergoing TOP), previous psychological/psychiatric history (associated with higher rates of post-traumatic stress disorder (PTSD) and depression ${ }^{[6]}$ following TOP), and low income (with women from low-income groups having higher admission rates for depression and PTSD after TOP ${ }^{[4]}$ ).

A recent survey involved 102 women undergoing TOP at two clinics in Johannesburg, SA (51 from each), one serving women with few economic resources (site 1) and the other serving women with adequate resources (site 2). The women were recruited and followed up for 3 months. At baseline, biographical data were obtained and there were no significant demographic differences between women recruited from the two sites.

The Beck Depression Inventory (BDI), ${ }^{[7]}$ a 21-item self-rating scale that is a validated and reliable instrument to assess depression, was administered to all the women.

To explore the meaning that the decision to undergo TOP had for women, the consensual qualitative research method $^{[8]}$ was used to analyse the transcripts of 22 women, 13 from site 1 and 9 from site 2, 1 month after the procedure. The women were administered a short questionnaire during a semistructured interview that sought to capture: (i) their reasons for TOP; (ii) their thoughts and feelings before the procedure; (iii) their thoughts and feelings after the procedure; and (iv) their experiences of the procedure (any positive and/or negative feelings about the actual procedure). To elicit symptoms of PTSD, together with the BDI, the revised version of the Impact of Events Scale (IES-R $)^{[0]}$ was administered to assess women's subjective experience, including intrusive thoughts, re-experiencing and avoidance reactions, each on a severity rating of $0-5$.

The women who willingly answered the question 'What was the reason for the TOP?' were generally younger, better educated and more likely to be employed than those who did not answer the question. There were no differences in scores for depression and PTSD in those who answered the question compared with those who did not. There were also no differences between the responses of women of lower socioeconomic status (site 1) and higher socioeconomic status (site 2).

Major themes and subthemes were identified independently by three reviewers, and consensus was obtained to ensure credibility and reliability of the interpretations made by the primary researcher. The following themes emerged related to personal characteristics (timing and readiness, e.g. not old enough; not ready for the responsibility; medical/health problems) and the women's circumstances, such as relationship with their partners (including partner coercion), financial worries and desire to continue education:

- Ambivalence was a common theme, e.g. 'I am relieved it's over but I feel really guilty', together with mixtures of

- Emotional distress (guilt, shame, regret, anxiety, depression, desperation/feeling compelled) and

- Fear and thoughts of death (should she go through with the procedure, or should she not terminate the pregnancy?).
With regard to the question 'What were your thoughts after the procedure?', ambivalence was again a common theme. Regarding respondents' experience of the actual procedure, the theme of ambivalence was once again prominent. Negative feelings about the experience were mainly personal feelings of guilt and shame and pain. Many women expressed surprise that there was so much pain, and wished that they could have been offered more pain relief, while others believed that they 'deserved' to be experiencing pain. Positive feelings were those of relief, feeling supported and happy, and feeling that they were treated well in a non-judgemental environment. It was important that they were managed in a safe environment, that the treating person was sympathetic and that they were told what to expect and how to relax.

While this survey 1 month after TOP did not allow for longer-term follow-up with regard to PTSD and depressive symptoms, it offers insight into the subjective feelings experienced by the women. Of note was the universality of the responses, regardless of socioeconomic, religious and cultural standing. Ambivalence and anxiety before the procedure has been reported in previous studies. Indeed, Lemkau ${ }^{[10]}$ claims that ambivalence is the norm for a woman who has an abortion, despite liberalisation of abortion laws, and that it is conceptualised in intrapsychic terms as 'personal conflict', her decision being in conflict with her personal values. ${ }^{[11,12]}$

The fact that women in this survey seemed relieved and objectively euthymic (as revealed by the completed PTSD and depression screening instruments), yet admitted to depressed mood/suicidal ideation/ conflicted emotions, emphasises the subjective experience of the TOP.

\section{Conclusion}

Our findings suggest that despite legislative changes and the promotion of non-judgemental attitudes among healthcare providers and indeed society as a whole, the experience of TOP remains contentious and difficult to study. Psychiatric sequelae such as depression and PTSD are not common, certainly not in the short term, but ambivalence with feelings of relief, guilt and anxiety before and after the procedure are common. Service providers should be alert to this and promote an empathic, safe and secure environment.

Ethics approval for the survey reported here was obtained from the South General Institutional Review Board at the University of California, Los Angeles (No. G07-06-057-01) and from the Human Research and Ethics Committee (HREC) of the University of the Witwatersrand (ethics clearance No. M070624).

\section{Ugash Subramaney}

Department of Psychiatry, School of Clinical Medicine, Faculty of Health Sciences, University of the Witwatersrand, Johannesburg, South Africa

\section{Gail Elizabeth Wyatt}

John K Williams

Semel Institute, Department of Biobehavioural Sciences, University of California, Los Angeles, USA

Correspondingauthor: U Subramaney (ugasvaree.subramaney@wits.ac.za)

Belsey EM, Greer HS, Lal S, Lewis SC Beard RW Predictive factors in the ennotion response to abottion: Kings Termination Study-IV. Soc Sci Med 1977;11(2):71-82. [http://dx.doi.org/10.1016/0037-7856(77)90002-6]

2. Adler NE. Emotional responses of women following therapeutic abortion. Am J Orthopsychiatry 1975;45(3):446-454. [http://dx.doi.org/10.1111/j.1939-0025.1975.tb02555.x]

3. Cohen L, Roth S. Coping with abortion. J Human Stress 1984;10(3):140-145. [http://dx.doi.org/10.10 80/0097840X.1984.9934968 
4. Reardon DC, Cougle JR, Rue VM, Shuping MW, Coleman PK, Ney PG. Psychiatric admissions of lowincome women following abortion and childbirth. CMAJ 2003;168(10):1253-1256.

Fergusson DM. Abortion and mental health. Psychiatr Bull 2008;32(9):321-324. [http://dx.doi. org/10.1192/pb.bp.108.021022]

6. Fergusson DM, Horwood LJ, Boden JM. Abortion and mental health disorders: Evidence from a 30-year longitudinal study. Br J Psychiatry 2008;193(6):444-451. [http://dx.doi.org/10.1192/bjp.bp.108.056499] . Beck AT, Beamesderfer A. Assessment of depression: The Depression Inventory. In: Pichot P, ed. Psychological Measurements in Psychopharmacology. Basel: S Karger, 1974:151-159.

. Hill CE, Knox S, Thompson BJ, Hess SA, Williams EN, Ladanay N. Consensual qualitative research: An update. Journal of Counselling Psychology 2005;52(2):196-205. [http://dx.doi.org/10.1037/0022-0167.52.2.196]
9. Weiss DS, Marmar CL. The Impact of Event Scale - revised. In: Keane JPWTM, ed. Assessing Psychological Trauma and PTSD. New York: Guilford Press, 1996:339-411.

10. Lemkau JP. Emotional sequelae of abortion: Implications for clinical practice. Psychol Women Q 1988. 12(4):461-472. [http://dx.doi.org/10.1111/j.1471-6402.1988.tb00978.x]

11. Adler NE, David HP, Major BN, Roth SH, Russo NF, Wyatt GE. Psychological responses after abortion. Science 1990;248(4951):41-44. [http://dx.doi.org/10.1126/science.2181664]

12. Major B, Cozzarelli C. Psychosocial predictors of adjustment to abortion. J Soc Issues 1992;48(3):121142. [http://dx.doi.org/10.1111/j.1540-4560.1992.tb00900.x]

S Afr Med J 2015;105(4):283-284. DOI:10.7196/SAMJ.9419 